\title{
ACTIVE VERSUS PASSIVE INVESTING: AN EMPIRICAL STUDY ON THE US AND EUROPEAN MUTUAL FUNDS AND ETFS
}

\author{
Desmond Pace, Jana Hili and Simon Grima
}

\begin{abstract}
Purpose - In the build-up of an investment decision, the existence of both active and passive investment vehicles triggers a puzzle for investors. Indeed the confrontation between active and index replication equity funds in terms of risk-adjusted performance and alpha generation has been a bone of contention since the inception of these investment structures. Accordingly, the objective of this chapter is to distinctly underscore whether an investor should be concerned in choosing between active and diverse passive investment structures.

Methodology/approach - The survivorship bias-free dataset consists of 776 equity funds which are domiciled either in America or Europe, and are likewise exposed to the equity markets of the same regions. In addition to geographical segmentation, equity funds are also categorised by
\end{abstract}

Contemporary Issues in Bank Financial Management

Contemporary Studies in Economic and Financial Analysis, Volume 97, 1-35

Copyright (C) 2016 by Emerald Group Publishing Limited

All rights of reproduction in any form reserved

ISSN: 1569-3759/doi:10.1108/S1569-375920160000097006 
structure and management type, specifically actively managed mutual funds, index mutual funds and passive exchange traded funds ('ETFs'). This classification leads to the analysis of monthly net asset values (' $N A V$ ') of 12 distinct equally weighted portfolios, with a time horizon ranging from January 2004 to December 2014. Accordingly, the riskadjusted performance of the equally weighted equity funds' portfolios is examined by the application of mainstream single-factor and multi-factor asset pricing models namely Capital Asset Pricing Model (Fama, 1968; Fama \& Macbeth, 1973; Lintner, 1965; Mossin, 1966; Sharpe, 1964; Treynor, 1961), Fama French Three-Factor (1993) and Carhart FourFactor (1997).

Findings - Solely examination of monthly NAVs for a 10-year horizon suggests that active management is equivalent to index replication in terms of risk-adjusted returns. This prompts investors to be neutral gross of fees, yet when considering all transaction costs it is a distinct story. The relatively heftier fees charged by active management, predominantly initial fees, appear to revoke any outperformance in excess of the market portfolio, ensuing in a Fool's Errand Hypothesis. Moreover, both active and index mutual funds' performance may indeed be lower if financial advisors or distributors of equity funds charge additional fees over and above the fund houses' expense ratios, putting the latter investment vehicles at a significant handicap vis-à-vis passive low-cost ETFs. This chapter urges investors to concentrate on expense ratios and other transaction costs rather than solely past returns, by accessing the cheapest available vehicle for each investment objective. Put simply, the general investor should retreat from portfolio management and instead access the market portfolio using low-cost index replication structures via an execution-only approach.

Originality/value - The battle among actively managed and index replication equity funds in terms of risk-adjusted performance and alpha generation has been a grey area since the inception of mutual funds. The interest in the subject constantly lightens up as fresh instruments infiltrate financial markets. Indeed the mutual fund puzzle (Gruber, 1996) together with the enhanced growth of ETFs has again rejuvenated the active versus passive debate, making it worth a detailed analysis especially for the benefit of investors who confront a dilemma in choosing between the two management styles.

Keywords: Active management; passive management; mutual funds; exchange traded funds; asset pricing models; modern portfolio theory 


\section{INTRODUCTION}

The funds' industry role has evolved to a central channel where both retail and professional investors can access a wide spectrum of markets, without retaining a directional exposure to a single instrument. Perceptibly, this allows for diversification effects to be augmented through the reduction of the specific risk associated with individual securities. Initially the main purpose for the formation of funds was to facilitate the pooling of investors' capital into a single structure, thereby exploiting economies of scale and scope by employing a professional portfolio manager and relevant expertise, reducing transaction costs vis-à-vis a do-it-yourself portfolio, whilst also permitting retail investors to access securities with elevated minimum investment thresholds which would be otherwise remote and not doable to invest in.

With regard to indexing prior to the existence of passive funds, it was practically unviable for investors to replicate effectively the returns of an underlying index or basket of instruments due to significant transaction costs and time constraints, owing to ongoing portfolio rebalancing. Moreover, if any physical replication was done by individual investors, the question would be that of whether the tracking quality was an adequate one. Subsequently admission to a broad range of securities is nowadays more feasible without encountering the aforementioned setbacks, leading to superior market efficiency, enhanced liquidity and induced financial markets' growth including market completion.

The establishment of different fund categories with distinct investment objectives has pioneered the confrontation involving active and passive investment structures, with the diversity between both ends emanating from the investment management style. More specifically, actively managed mutual funds aim to outperform the market portfolio proxied by major stock indices, whereas passive funds merely endeavour to replicate an underlying index, whilst preserving tracking error to a minimum. Undoubtedly, due to various factors including research costs and maintenance of the fund's objective, actively managed mutual funds charge higher fees vis-à-vis index funds, as the latter's solely concern is tracking the benchmark index as close as possible, with no effort exhausted on searching for undervalued and/or overvalued securities.

It is of common knowledge that albeit a percentage of actively managed mutual funds may indeed outperform the market and hence outshine passive funds, the net returns for active investors may be equivalent to or less than index funds' net returns, owing to higher management fees 
and transaction costs. Indeed, it is worth researching whether the expenses incurred in attempting to outperform the market do actually cancel the efforts of the outperformance component over and above the market portfolio whilst also considering risk into the equation, thereby resulting in the Fool's Errand Hypothesis. In such case if riskadjusted returns, net of fees, transpire to be equivalent, active and passive investors will be indifferent which way to elect. The issue is that with passive funds the market portfolio is 'guaranteed' as long as the tracking error isn't abnormal, whereas with actively managed mutual funds performance may either be better or even worse than the market index gross of fees, let alone after costs. This portrays a dilemma as to whether investors should opt for passive or active investment funds. Another concern is that apart from the conventional index funds, investors can nowadays access index replication investments via passive ETFs, therefore the uncertainty of choosing the optimal structure is further amplified.

Passive ETFs are akin to index funds, being a basket of instruments pooled together to replicate the returns of a specific benchmark. Alike to other passive investment vehicles, ETFs also provide a relatively costeffective exposure to a wide spectrum of securities including equities, fixed income, commodities, currencies, real estate and major indexes. Apart from the initial passive types, active ETFs were gradually introduced in the market and this trend is expected to augment further. The latter instruments are a priori deemed as perfect or close substitutes for actively managed mutual funds.

Succinctly, ETFs are more liquid as they trade intraday on a stock exchange like any publicly listed security, whereas index and actively managed mutual funds are only priced at end of day via the NAV calculation. Being exchange tradable, less liquid ETFs may be inefficiently priced, at least intraday, and thereby enabling investors to long-sell under-priced and short-sell over-priced ETFs relative to their intraday indicative values. The characteristic of being exchange tradable makes ETFs a crossbreed between a mutual fund and a stock, essentially a product of financial innovation.

Ultimately the construction of these innovative instruments has provided new horizons for both retail and institutional investors, including exposure to a diversified index or portfolio through leverage and possibly arbitrage opportunities, due to the eventuality of ETFs' intraday prices deviating from their underlying portfolio values. Yet such arbitrage may be short-lived especially during wide mispricings, since ETF structures 
enable approved parties to create and redeem ETFs at the respective NAV at end of trading, hence reducing price inefficiencies by enhancing market efficiency.

For the benefit of investors, this chapter aims to provide robust conclusions on distinct equity fund structures by tackling the successive research questions and hypothesis.

Existing literature suggests that the majority of actively managed mutual funds tend to underperform their underlying benchmarks, gross and net of fees (Blake, Elton, \& Gruber, 1993; Gruber, 1996; Harper, Madura, \& Schnusenberg, 2006; Malkiel, 1995; Rompotis, 2009; SPIVA, 2013, 2014), and hence passive structures including ETFs tend to be the wiser choice for investors. Therefore, is it rational to consider that passive management actually outperforms active? If this is the case, what explains the existence of the mutual fund puzzle (Gruber, 1996) along the past two decades?

Secondly, being close substitutes and index replication structures, ETFs and index funds are expected to mimic their underlying benchmarks, and thus calculated alphas are expected to be inexistent. In particular, existence of high alphas should be solely capturing a high tracking error. Consequently, given that passive ETFs and index funds do not seek to outperform a relative benchmark but rather track, calculated alphas will be negligible in case both structures have equivalent expense ratios. Hence, is it practical to solely consider passive management structures which actually charge the lowest expense ratios vis-à-vis their peers?

\section{AIM OF THE STUDY}

The aim of this chapter is to distinctly underscore whether an investor should be concerned in choosing between active and diverse passive investment structures. It will focus on measuring the generated alphas of actively managed mutual funds, index funds and passive ETFs, hence undertaking a risk-adjusted return approach. The researchers aim to grant a recommendation to the general investor to successively distribute investment capital effectively by procuring the highest alphas and risk-adjusted returns. Ultimately the study pursues to shed light on whether an investor benefits from selecting among active and passive investment funds, amid fierce competition between such collective investment structures and the recent explosive growth of exchange tradable funds. 


\section{LITERATURE REVIEW}

Fundamental theories, asset pricing models and evidence on diverse fund structures are central to this research, all of which are reviewed in this section. Indeed the foremost reliable literature including research papers feature in this partition.

\section{Theoretical Background}

Markovitz' portfolio theory (1952a, 1952b) and the CAPM (Fama, 1968; Fama \& Macbeth, 1973; Lintner, 1965; Mossin, 1966; Sharpe, 1964; Treynor, 1961) are the cornerstones which pioneered the birth and growth of asset pricing models. Indeed the anomalies' literature and CAPM's sceptics notably Roll (1977) indirectly encouraged the development of the basic model to extend its structure further. CAPM's enhancements predominantly ensued into Jensen's Alpha, the Three-Factor and Four-Factor Models as proposed by Fama and French (1993) and Carhart (1997), respectively. Complimenting these asset pricing models are a number of risk-adjusted performance measures primarily the Treynor ratio (1965), Sharpe ratio (1966) and Jensen's alpha (1968).

\section{CAPM and Risk-Adjusted Models}

Performance evaluation chiefly evolved from the establishment of CAPM, which was introduced as an asset pricing model. The CAPM as a theoretical model follows the mean-variance efficient concept initiated by Markowitz (1952a, 1952b). Put simply this theory entails that an investor will request the highest return for a given level of risk or the lowest risk for a given level of return, leading to the formation of portfolios on the efficient frontier. Specifically, investors can design the efficient frontier by employing the CAPM formula (Eq. (1)), which exhibits the relationship between risk and return via the market or beta risk, hence termed single-factor model.

$$
\begin{aligned}
& E\left(R_{P}\right)=R_{f}+\beta\left[E\left(R_{m}\right)-R_{f}\right] \\
& \text { CAPM (Source: Sharpe, 1964) }
\end{aligned}
$$

where $E\left(R_{p}\right)$ refers to the individual's portfolio expected return, $R_{f}$ incorporates the return on risk-free securities, $\left[E\left(R_{m}\right)-R_{f}\right]$ illustrates the excess 
return of the market portfolio over and above the risk-free rate and the $\beta$ coefficient represents the strength of the relationship between the investor's portfolio and the market portfolio.

An important concept of CAPM is that an investor is only compensated for systematic or market risk, as it cannot be diversified away. Put differently, no compensation is supplied for firm-specific risk since it can be reduced by diversification by incorporating more securities in a portfolio. The direction and extent of co-movement with market risk is computed by beta (Eq. (2)).

$$
\beta_{P}=\frac{\operatorname{cov}\left(R_{P}, R_{m}\right)}{\sigma_{m}^{2}}
$$

Beta (Source: Sharpe, 1964)

A beta of 1 connotes a perfectly positively correlation between an investor's portfolio and market portfolio. Therefore, a specific return generated by the market should be identically replicated by the investor's portfolio. Portfolios with a beta of 0 provide return equivalent to the risk-free rate, and hence are uncorrelated with the market returns. Portfolios with a beta of -1 inversely replicate the market, thus distribute perfectly opposite returns to those of the market. As a side note, investors typically expand portfolio betas throughout economic growth but contract such betas during turbulent times.

The formation of CAPM has long substantiated that computing return on its own simply supplies a trivial outcome. This signifies that portfolio return has to be assessed in tandem with its underlying risk to undertake a correct investment decision. This has led to the creation of two distinguished risk-adjusted ratio proposed by Sharpe (1966) (Eq. (3)) and Treynor (1965) (Eq. (4)), which concisely underscore the amount of return per each unit of risk.

$$
S_{P}=\frac{E\left(R_{P}\right)-R_{f}}{\sigma_{P}}
$$

Sharpe Ratio (Source: Sharpe, 1966)

$$
T_{P}=\frac{E\left(R_{P}\right)-R_{f}}{\beta_{P}}
$$

Treynor Ratio (Source: Treynor, 1965) 
Though a priori both ratios may appear analogous, this is not the case as in the denominator a diverse path is employed. The Sharpe ratio is concerned with the portfolio's standard deviation by utilising the capital market line methodology, whereas the Treynor ratio adopts the portfolio beta via the security market line approach. Pro Roll's critique will noticeably favour the Sharpe ratio, as the latter does not make reference to a specific benchmark, which is unobservable and inexistent (Roll, 1977).

\section{Single-Factor Regression Model}

The single-factor model as proposed by Jensen (1968) remains to date a prevalent methodology for quantifying managers' skill and fund performance via alpha estimation (Eq. (5)). Jensen's alpha builds on the standard CAPM and hence assumes its empirical validity and robustness, predominantly that portfolio returns are explained by a linear relationship with beta plus the risk-free rate.

$$
\begin{gathered}
E\left(R_{p}\right)-R_{f}=\alpha_{P}+\beta_{P}\left[E\left(R_{M}\right)-R_{f}\right]+\varepsilon_{P} \\
\text { Jensen's Alpha (Source: Jensen, 1968) }
\end{gathered}
$$

where $E\left(R_{p}\right)-R_{f}$ represent the excess return on portfolio $p$, as a result of the exposure to the market risk premium $\left\{\beta_{P}\left[E\left(R_{m}\right)-R_{m}\right]\right\}$, plus $\varepsilon_{P}$ being the error term and the notorious Jensen's alpha $\left(\alpha_{p}\right)$. Put simply a positive $\alpha_{p}$ implies that a portfolio manager has yielded higher risk-adjusted return than the underlying index or benchmark signifying skill and/or good luck. Conversely a negative alpha denotes a manager inability to generate the minimum expected return vis-à-vis the market portfolio, hence displaying lack of skill and/or bad luck.

Nevertheless supplementary research depicts that CAPM including Jensen's alpha is not able to explain returns entirely. Indeed stocks with certain characteristics tend to generate higher returns than that predicted by CAPM, leading to the introduction of multi-factor regression models.

\section{Multi-Factor Regression Models}

The first empirical evidence for testing the CAPM for equity portfolios via the SML demonstrated a robust positive relationship between mean returns and beta (Black, Jensen, \& Scholes, 1972; Fama \& Macbeth, 1973). Yet as further empirical studies were undertaken, less encouraging support for CAPM was shaping, ensuing in the anomalies' literature and declaring that beta is dead. 
Basu (1977), Banz (1981), Fama and French (1993) authenticated that CAPM is mis-specified, since equity portfolios exhibiting large exposures to the size and/or value effect on average generate higher returns than that predicted by the single-factor model. Basu (1977) observed that portfolios encompassing value stocks outperformed growth stocks. Banz (1981) consecutively identified the small size effect, where small cap portfolios outshined larger caps. This evidence has led to consider the rejection of the Efficient Market Hypothesis ('EMH') and that securities' prices could possibly be biased, as an investor could obtain abnormal returns by going long value stocks signalled by a low price to earnings ratio, and small caps denoted by market capitalisation size. Nevertheless a general explanation for higher returns is that value stocks have a higher exposure to bankruptcy risk, whereas small caps have a larger exposure to liquidity risk. This means that higher returns are merely a compensation for undertaking a higher risk and hence this does not lead to a breakdown in the EMH. Although Basu (1977) and Banz (1981) evidence may have put some uncertainties on the EMH, it had geared up the trail for the construction of multi-factor models and/or improvement of existing ones. Indeed the shortcomings and naive approach of CAPM has led to notable theoretical and empirical research confirming that expected returns can be described by a number of variables via a multi-factor model leading to CAPM enhancement or even the creation of other asset pricing models (Carhart, 1997; Fama \& French, 1993; Jagannathan \& Wang, 1996; Ross, 1976).

A case in point was the development of the Arbitrage Pricing Theory by Ross (1976), which is established on the law of one price implying no arbitrage opportunities. Similarly to CAPM for fully diversified portfolios, the model assumes that idiosyncratic risk becomes inexistent, and hence expected returns are only explained by the exposure to risk factors. In Arbitrage Pricing Theory ('APT'), the model is constructed either as a single-factor or a multi-factor. For this reason, as an asset pricing model the APT is more flexible than CAPM, since it can absorb a variety of risk factors even in the absence of theoretical background. More specifically the APT assumes that expected returns can be explained by a single or a number of risk factors, yet it does not visibly sketch out which risk factors to employ. For instance the utilised risk factors can be stock indexes, fundamental variables, firm characteristics (Fama \& French, 1992), macroeconomic factors (Chen, Roll, \& Ross, 1986) and other generic factors.

Fama and French (1993) utilised previous empirical work predominantly from Basu (1977) and Banz (1981) to develop a Three-Factor model (Eq. (6)) for the purpose of explaining asset returns. Fama and French (1993) used firm 
characteristics, namely size proxied by market capitalisation (SMB) and book to market ratio (HML) to gauge systematic risk exposure.

$$
R_{P}-R_{f}=\propto_{p}+\beta_{0 P}\left(R_{M}-R_{f}\right)+\beta_{1 P} S M B+\beta_{2 P} H M L+\varepsilon_{P}
$$

Fama French Three-Factor Model (Source: Fama \& French, 1993)

The SMB (small minus big) risk factor adjusts for the exposure of the general outperformance of small cap portfolios over large ones. The HML (high minus low) variable corrects for the exposure of value stock portfolios, measured by a high book to market ratio, which typically outperform growth equity portfolios exhibiting low book to market ratios. The SMB is constructed by grouping small caps (S), being those equities with market cap below the median, and grouping large caps (B), that is, those firms with above the median market cap. Once both groups are finalised, then a risk premium is formulated by subtracting (M) the two and obtain an excess return. For HML a similar procedure is performed as stocks are sorted depending on book to market ratio into three distinct classes. The top $33 \%$ of stocks with the highest book to market ratio are categorised as $\mathrm{H}$, whilst the bottom $33 \%$ of equities with the lowest book to market ratio are grouped as L. Then the risk premium or excess return between the two is calculated by subtracting (M). A high beta for the SMB risk factor would illustrate that a portfolio has a large exposure to small caps. Similarly a high beta for HML would signify that a fund has a greater exposure to value stocks rather than growth equities. In practice the Fama French Three-Factor model aids to illustrate whether a fund manager is generating returns given skill, or simply due to a greater risk exposure for small caps and value stocks, therefore reducing noise from alpha.

As an effort for cleaning alpha further, Carhart (1997) added another risk factor capturing momentum effects (Eq. (7)), which theoretically was introduced by Jegadeesh and Titman (1993). The momentum anomaly demonstrates that buying past winners and short selling past losers generates abnormal returns. Put simply, top performing equities are expected to continue performing well in the future and vice versa. Therefore, the momentum risk factor corrects for the overexposure to past winning stocks which generally outperform past losing stocks. The MOM risk factor is the risk premium or excess return of a past winner portfolio over the loser portfolio. It is composed by grouping an equally weighted average of last year's top $30 \%$ high performing equities versus an equally weighted average of last year's bottom $30 \%$ lowest performing ones, then taking the difference between the two. 


$$
\begin{gathered}
R_{P}-R_{f}=\propto_{P}+\beta_{0 p}\left(R_{M}-R_{f}\right)+\beta_{1 P} \mathrm{SMB}+\beta_{2 P} \mathrm{HML}+\beta_{3 p} \mathrm{MOM}+\varepsilon_{P} \\
\text { Carhart Four-Facctor Model (Source: Carhart, 1997) }
\end{gathered}
$$

To recapitulate, Carhart's (1997) Four-Factor model evolved from the Fama and French (1993) Three-Factor model, where the latter model was derived by employing earlier empirical work from Basu (1977), Banz (1981) and Jegadeesh and Titman (1993). Even though such multi-factor models may be criticised for lacking theoretical foundation, numerous empirical studies employed these models to assess portfolio performance. Indeed the widespread usage of these factor models confirms that several researchers endorse their validity.

\section{Evidence on Active and Passive Management}

Fund managers' ability, predominantly securities' selectivity skills, has had a fundamental role in the financial literature. The majority of researchers clinch that active investment strategies tend to underperform passive ones, prior and post expenses (Blake et al., 1993; Bogle, 1998; Gruber, 1996; Harper et al., 2006; Malkiel, 1995; Rompotis, 2009; SPIVA, 2013, 2014). Furthermore, distinguished researchers namely Treynor (1965), Sharpe (1966) and Jensen (1968) all confirm that risk-adjusted performance of actively managed mutual funds underperforms a passive strategy after adjusting for expenses, at least for the period studied.

Malkiel (1995) investigated the performance and survivorship bias for equity mutual funds, authenticating that the latter typically underperform their underlying index, even gross of fees. Frino and Gallagher (2001) equivalently demonstrated that throughout their period of study, the Standard \& Poor's 500 index fund boasted superior risk-adjusted return net of fees. Moreover Bogle (1998) presents a trade-off between fund selection and low expense funds, outlining that it would be prudent to select low expense funds at the expense of limiting fund selection.

Malkiel (1995) also suggests that performance persistence was present in the past and thus an investor could generate excess returns using historical data at least for a decade in the 1970s. As markets became efficient and investors more informed, such information was gradually reflected in instruments' prices, and as a result excess returns along with arbitrage opportunities disappeared. Yet Kuo and Mateus (2006), Rompotis (2007) together with Andreu, Swinkels, and Tjong-A-Tjoe (2012) disagree and 
exhibit evidence of performance persistence. More specifically Andreu et al. (2012) highlight country and industry momentum using ETFs and conclude that investors are able to yield an excess return of 5\% per annum by buying previous winners and shorting previous losers. Rompotis (2007) emphasises the existence of a November effect for ETFs, whilst also outlining November as the best month for index replicating ETFs in terms of tracking ability. Indeed Rompotis (2007) states that given the blend of high positive performance, low risk and minimum tracking error in such month, it signifies an opportunity for investors to obtain excess returns, which on average can beat the buy and hold strategies on a five-year horizon.

Harper et al. (2006) contrasted the performance of actively managed closed ended funds with passive ETFs. Analogous to the mainstream literature, findings depict that passive instruments reveal higher alphas and superior Sharpe ratios. More distinctively, on average closed ended funds exhibited negative alphas. One motivation was that ETFs' higher alphas and risk-adjusted returns may be driven by diversification effects when holding positions in globally diversified portfolios.

Rompotis (2009) applied the active versus passive argument to ETFs, by examining the performance of actively and passively managed ETFs. As a continuation to the existing literature, Rompotis (2009) authenticated previous research by demonstrating that actively managed ETFs underperform their counterparts plus market indexes. Furthermore it was observed that market timing and selection skills of active ETFs are poor. The same results in terms of manager skills emerged for passive ETFs, yet since the latter do not try to beat the market but only replicate a benchmark, it is trivial to analyse or search for such skills.

In addition to the available literature, Standard \& Poor's Dow Jones Indices Versus Active (SPIVA) suggest that a large percentage of US actively managed equity mutual funds underperform their benchmarks including passive funds. From 2008 to 2013, more than 70\% of large-cap funds holding the Standard \& Poor's 500 as their benchmark underperformed. During 2013 and 2014 , above $60 \%$ of large cap and around $70 \%$ of small cap underperformed their relative benchmarks net of fees (SPIVA, 2013, 2014). The phenomenon that passive funds may indeed outperform actively managed mutual funds is not solely present for equity mutual funds. Blake et al. (1993) employed models for US bond mutual fund samples to determine performance vis-à-vis their benchmarks. Aggregately it was established that for diverse bond categories, fixed income funds underperform their related benchmarks net of fees. Moreover a robust regression equation illustrated that a percentage unit increase in management fees yields a percentage unit 
decrease in bond fund return. Ultimately the core source for bond fund underperformance are the higher costs incurred by investors, generating inefficiency compared to the underlying index. Also historical performance adjusted for survivorship bias was found to have no explanatory power for future return predictability, and this was also confirmed by Malkiel (1995).

It is evident that existing literature suggests that investors will fare better by employing a buy and hold approach. Nevertheless even though actively managed funds underperform and charge higher fees on average, their explosive growth during the last two decades has been remarkable. Gruber (1996) refers to this setting as the actively managed mutual fund puzzle. Still Minor (2001) states that there is potential for actively managed mutual funds to outperform their peers during certain periods, and hence time horizon is a major factor when analysing data. Yet Sharpe (1991) endorsed that prior transaction costs, the aggregate return of all actively managed portfolios will be equivalent to the market portfolio, and hence equal to passively managed portfolios. But post fees, the aggregate return of all actively managed portfolios will be less than the passive portfolios, given higher friction costs.

Since the majority of the literature reckons that passive outperforms active, this should result in the Grossman-Stiglitz paradox (Grossman \& Stiglitz, 1980). If this holds in practice, actively managed mutual funds will cease to exist given their underperformance, ensuing in an increased demand for replication structures. This will consecutively trigger markets to become less efficient as fewer investors and portfolio managers will endeavour to beat the market. Such scenario will eventually lead to inferior market efficiency, and hence would be the optimal moment to attempt in outperforming the market. Consequently a priori, although it may be better to elect index funds in efficient markets, this may not be the case in less efficient markets given the existence of arbitrage opportunities.

\section{Evidence on Index Mutual Funds and Passive ETFs}

Dellva (2001) states that small investors may find ETFs less attractive than index funds due to higher initial entry costs, even though management fees are relatively cheaper for ETFs. Simultaneously due to the in-kind creation and redemption procedure, ETFs provide considerable tax advantages (Bernstein, 2002; Dellva, 2001; Kostovetsky, 2003; Poterba \& Shoven, 2002). This is since current ETF investors are only liable for paying capital gains tax once their position is closed and not at the end of each financial 
year. Yet Bernstein (2002) states that regular trading will extinguish ETFs' advantages including taxation benefits, and for this reason recommends them for long-term horizons. Indeed Bernstein outlines that in 2001, whilst a mutual fund was being held for three years, SPDR's ETFs were only being kept for 19 days on average. Such statistic is outdated and hence the scenario may possibly have changed. Also Elton, Gruber, Comer, and Li (2002) argue that a drawback of some ETFs is that investors cannot receive interest on their dividends. However this disadvantage can be circumvented, as ETFs can be structured as open ended investment company or Unit Investment Trusts (Elton et al., 2002).

Kostovetsky (2003) summarised the significant disparities between passive mutual funds and ETFs. The two structures vary in terms of management fees, shareholder transaction costs, taxation settlement and other qualitative factors such as the convenience and ease to buy or sell an ETF intraday at a transparent market price as opposed to the end of day NAV of an index mutual fund. As a concept the bid-offer spreads paid on passive mutual funds correspond to the bid-ask spread and brokerage fees on ETFs, indicating that both structures charge entry and exit fees apart from management ones. Gastineau (2004) tackled the operating efficiency issue, instead of addressing the lower expense ratios and tax efficiency of ETFs. Gastineau (2004) concluded that index mutual funds possess greater flexibility and superior operating efficiency, as these can outperform their underlying index and relative ETFs, however at the expense of augmenting tracking error by not undertaking a complete replication.

Engle and Sarkar (2006), Rompotis (2006) and Aber, Li, and Can (2009) closely examined trading patterns for ETFs. Aber et al. (2009) together with Rompotis (2006) observed that ETFs are more likely to be priced at a premium vis-à-vis their actual NAV or intraday indicative value, implying a higher price to earnings ratio. Engle and Sarkar (2006) further demonstrated that international ETFs have a tendency to significantly deviate from the actual NAV, more than local ETFs. Aber et al. (2009) also established that index mutual funds exhibit lower tracking error than their relative ETFs during their period of study. This is denied by Rompotis (2008), stating that index funds and ETFs exhibit analogous tracking ability on average. One motive for such divergence may possibly be the different data employed. Interestingly, Johnson (2009) found that a core factor for explaining tracking error was the difference in trading hours between non-US-domiciled ETFs which mimicked US benchmarks.

Guedj and Huang (2008), Rompotis (2008) and Agapova (2009) focused on the coexistence and substitutability of index mutual funds and ETFs, 
highlighting market segmentation. Guedj and Huang (2008) observed that the mutual fund structure supplies liquidity shocks' insurance for investors, and therefore it is preferred by risk-averse and short-term horizon investors. Rompotis (2008) states that although both structures deliver similar solutions, conservative equity and low risk-averse mutual funds investors together with professional investors who cannot use derivatives have a preference for ETFs, whilst conventional retail investors usually avoid ETFs. Likewise Agapova (2009) explained that even though ETFs and index mutual funds are seen as perfect substitutes, they cannot be categorised as such, owing to structural variations leading to the so-called 'clientele effect'. Guedj and Huang (2008), Svetina and Wahal (2008) and Agapova (2009) concur that the existence of both vehicles resulted into enhanced market completion. Specifically Svetina and Wahal (2008) remark that approximately only $17 \%$ of the ETF universe compete directly with index mutual funds. With regard to the remaining $83 \%$, they are relatively specific niche areas where passively managed mutual funds are not usually present, and this is also evidenced by Guedj and Huang (2008).

\section{METHODOLOGY AND DATA}

The applied research and data methodology have been extensively utilised in research papers as it consents huge volume of data to be examined, providing wider analysis and more robust conclusions (Banz, 1981; Basu, 1977; Carhart, 1997; Fama \& French, 1993; Jegadeesh \& Titman, 1993).

\section{Sample Description}

NAV data for all American and European-domiciled actively managed equity mutual funds, index equity mutual funds and equity ETFs, was gathered from the Thomson Reuters Eikon Fund Screener. The monthly NAVs cover the period from December 2003 to December 2014 for each individual investment vehicle, yielding 133 observations for funds surviving the whole period of investigation. Those funds which did not endure the entire period of study are also included in the dataset to eliminate survivorship bias.

Survivorship bias is a shortcoming that samples are prone to if liquidated, merged or dead funds are entirely ignored from a dataset. The repercussions will be a bias towards funds which are still alive overstating 
the returns of a sample, as on average dead funds typically underperform. The Thomson Reuters Eikon Fund Screener enables data samples to be free of survivorship bias by including Liquidated and Merged funds with Active and Primary Funds in the Funds Status criteria.

An array of criteria was established in the Thomson Reuters Eikon Funds Screener to acquire the desired mutual funds and ETFs based on a list of variables. The criteria include Fund Status (Active, Liquidated, Merged, Primary fund), Asset Universe (Mutual Funds or ETFs), Asset Type (Equity), Domicile (US or European), Geographical Focus (US or European) and Strategy (Index Replication or otherwise). With regard to the Strategy variable, any funds which are not passive in nature and do not perform index replication methods are considered to be actively managed.

The selection criteria yielded the NAVs for US- and European-domiciled Active and Passive Equity Mutual Funds and Passive Equity ETFs, with a geographical focus to the United States and Europe (Table 1). The fund dataset provided by Thomson Reuters Eikon Funds Screener accumulated to 776 investment vehicles, representing the research fund universe. NAV data for all individual funds was subsequently grouped into distinct categories, forming 12 equally weighted portfolios to gauge aggregated results for each subsample (Table 2).

Performance examination of the equally weighted portfolios' for 10 financial years is deemed satisfactory especially given the diverse economic cycles encountered, notably the turmoil of the 2007-2008 global financial crisis, the subsequent European Sovereign Debt crisis and the 2014 Oil crisis inter alia. Such time horizon could not be exceeded given that certain passively managed funds, specifically ETFs are a 'recent' innovation and hence lack historical data. Moreover below a 10-year sample data might encompass plenty of noise rather than 'normal' patterns. Therefore a decade of financial data is seen as the optimal period for the research.

Fund portfolios' performance are analysed via three major asset pricing namely the Capital Asset Pricing Model (Fama, 1968; Fama \& Macbeth, 1973; Lintner, 1965; Mossin, 1966; Sharpe, 1964; Treynor, 1961), Fama French Three-Factor Model (1993) and Carhart FourFactor Model (1997), outlined earlier. A crucial aspect for forming portfolios was the extensive presence of heteroscedasticity and serial correlation in residuals, when analysing individual funds' residual diagnostics. This violated CLRM assumptions, hence a modification in the methodology to construct equally weighted portfolios was requisite. Indeed undertaking regression analysis for individual securities and/or funds is susceptible to huge noise generated by idiosyncratic risk, whilst when merging into portfolios 'normal conditions' are reinstated. 
Table 1. Funds' Sample Data and Portfolio.

\begin{tabular}{llcc}
\hline Origin & \multicolumn{1}{c}{ Style } & \multicolumn{2}{c}{ Geographical Focus } \\
\cline { 3 - 4 } & & USA & Europe \\
\hline US mutual funds & Index replication & 152 & 5 \\
& Active & 184 & 4 \\
EU mutual funds & Index replication & 20 & 88 \\
& Active & 34 & 188 \\
US ETFs & Index replication & 53 & 3 \\
EU ETFs & Index replication & 3 & 42 \\
\hline
\end{tabular}

Table 2. Equally Weighted Portfolios Representation.

\begin{tabular}{|c|c|}
\hline Portfolio Code & Representation \\
\hline EU_ETF_GF_EU_IR_PORTFOLIO & $\begin{array}{l}\text { European passive ETF with European geographical } \\
\text { focus }\end{array}$ \\
\hline EU_ETF_GF_US_IR_PORTFOLIO & European passive ETF with US geographical focus \\
\hline EU_MF_GF_EU_ACT_PORTFOLIO & $\begin{array}{l}\text { European active mutual fund with European } \\
\text { geographical focus }\end{array}$ \\
\hline EU_MF_GF_EU_IR_PORTFOLIO & $\begin{array}{l}\text { European passive mutual fund with European } \\
\text { geographical focus }\end{array}$ \\
\hline EU_MF_GF_US_ACT_PORTFOLIO & $\begin{array}{l}\text { European active mutual fund with US geographical } \\
\text { focus }\end{array}$ \\
\hline EU_MF_GF_US_IR_PORTFOLIO & $\begin{array}{l}\text { European passive mutual fund with US geographical } \\
\text { focus }\end{array}$ \\
\hline US_ETF_GF_EU_IR_PORTFOLIO & US passive ETF with European geographical focus \\
\hline US_ETF_GF_US_IR_PORTFOLIO & US passive ETF with US geographical focus \\
\hline US_MF_GF_EU_ACT_PORTFOLIO & $\begin{array}{l}\text { US active mutual fund with European geographical } \\
\text { focus }\end{array}$ \\
\hline US_MF_GF_EU_IR_PORTFOLIO & $\begin{array}{l}\text { US passive mutual fund with European geographical } \\
\text { focus }\end{array}$ \\
\hline US_MF_GF_US_ACT_PORTFOLIO & US active mutual fund with US geographical focus \\
\hline US_MF_GF_US_IR_PORTFOLIO & US passive mutual fund with US geographical focus \\
\hline
\end{tabular}

\section{Asset Pricing Models, Benchmarks and Proxies}

Prior to employing asset pricing models, it is crucial underlining the applied equity benchmarks and risk-free rate proxies. The Standard \& Poor's 500 and the EUROSTOXX are used as equity market portfolios proxies, given widespread recognition as mainstream equity benchmarks for their relevant region. The end-of-month trading price of both benchmarks is acquired from Thomson Reuters Eikon. 
As for the risk-free rate, the 3-Month US Treasury Bill is generally utilised, and likewise is chosen as a proxy. More specifically the 3-Month US Treasury Bill monthly ask yield is selected, as it reflects the actual return for retail and institutional investors. The risk-free rate plays an important role in asset pricing models, since investors are merely concerned with excess returns, that is the return over and above the risk-free rate. Nevertheless given late and existing global economic conditions, the riskfree rate has immensely declined across the years to near zero levels.

With regard to Fama French Three-Factor model and Carhart FourFactor model, the data for the relevant risk factors is accessed from Kenneth French online library. Data for HML being the return-on-value stocks portfolios less growth stocks portfolios' return; SMB that is, small cap portfolios minus large cap stocks portfolios' return; and MOM representing the momentum factor, put simply going long-sell winners' equity portfolios and short-sell losers' equity portfolios. These risk factors are necessary to perform regression analysis and statistical inferences for capturing alpha if present, for the equally weighted portfolios. Specifically the SMB, HML and MOM European risk factors are employed for the European exposed equity fund portfolios. Similarly the SMB, HML and MOM US risk factors are applied for the US-exposed stock fund portfolios. This procedure is necessary as application of US research factors for European focused equity portfolio funds and vice versa delivers feeble explanatory power.

\section{Regression Models}

The standard CAPM together with the Three and Four-Factor models are implemented to exhibit any alpha presence for the distinct equally weighted equity fund portfolios, ensuing into 36 regressions. ${ }^{1}$ The three models can be represented as follows:

$$
\ln \Delta R_{p i, t}-\ln \Delta R_{f, t}=\propto_{i}+\beta_{i 1}\left\{\ln \Delta R_{m i, t}-\ln \Delta R_{f, t}\right\}+\varepsilon_{i, t}
$$

The Market Model

where

ln $\Delta R_{p i t}$ is the natural logarithm change on the return of portfolio $i$ at time $t$ $\ln \Delta R_{f, t}$ denotes the natural logarithm change on the risk-free rate at time $t$ $\ln \Delta R_{p i, t}-\ln \Delta R_{f, t}$ implying fund excess returns for portfolio $i$ at time $t$ $\propto_{i}$ is the alpha for portfolio $i$ 
$\beta_{k}$ (for $k=1$ ) stands for the sensitivity of fund portfolios' excess returns to the exogenous variable

$\ln \Delta R_{m i, t}$ is the natural logarithm change on the market portfolio proxy at time $t$

$\ln \Delta R_{m i, t}-\ln \Delta R_{f, t}$ signifies market excess returns at time $t$

$\varepsilon_{i, t}$ embodies the residual for portfolio $i$ assumed to be homoscedastic, normally distributed and with zero mean.

$$
\begin{aligned}
\ln \Delta R_{p i, t}-\ln \Delta R_{f, t}= & \propto_{i}+\beta_{i 1}\left\{\ln \Delta R_{m i, t}-\ln \Delta R_{f, t}\right\}+\beta_{i 2}\left\{\mathrm{SMB}_{t}\right\} \\
& +\beta_{i 3}\left\{\mathrm{HML}_{t}\right\}+\varepsilon_{i, t}
\end{aligned}
$$

The Three-Factor Model

where

$\beta_{k}$ s (for $k=1-3$ ) stand for the sensitivity of portfolios' excess returns to the explanatory variables

$\left\{\mathrm{SMB}_{t}\right\}$ indicates the Small Minus Big risk factor for small cap exposure at time $t$

$\left\{\mathrm{HML}_{t}\right\}$ represents the High Minus Low risk factor for value stock exposure at time $t$.

$$
\begin{aligned}
\ln \Delta R_{p i, t}-\ln \Delta R_{f, t}= & \propto_{i}+\beta_{i 1}\left\{\ln \Delta R_{m i, t}-\ln \Delta R_{f, t}\right\}+\beta_{i 2}\left\{\mathrm{SMB}_{t}\right\} \\
& +\beta_{i 3}\left\{\mathrm{HML}_{t}\right\}+\beta_{i 4}\left\{\mathrm{MOM}_{t}\right\}+\varepsilon_{i, t}
\end{aligned}
$$

The Four-Factor Model

where

$\beta_{k}$ s (for $k=1-4$ ) stand for the sensitivity of portfolios' excess returns to the explanatory variables

$\left\{\mathrm{MOM}_{t}\right\}$ is the Momentum risk factor for momentum exposure at time $t$.

\section{OLS and CLRM Assumptions}

Application of regression analysis entails routine diagnostic checks to avoid violation of assumptions under the CLRM (Classical Linear Regression Model). Such breach will affect the desirable properties of estimators under OLS which will no longer remain BLUE (Best, Linear, Unbiased, Estimator), predominantly influencing hypothesis testing ensuing into type 1 and type 2 errors. 
There are five CLRM assumptions which need not be violated for OLS to well function (Brooks, 2008). The first assumption is $E\left(u_{t}\right)=0$, implying that the average value of residual terms is zero. This assumption is circumvented and never violated by including a constant term in the regression. Secondly var $\left(u_{t}\right)=\sigma^{2}<\infty$ signifying that the variance of the residuals is constant hence homoscedastic. The White Heteroscedasticity test will verify such data property. Thirdly $\operatorname{cov}\left(u_{i}, u_{j}\right)=0$ outlining that the covariance of the error term overtime equals zero and hence there is no serial correlation. The Breush Godfrey and Durbin Watson tests will authenticate whether residuals are autocorrelated or otherwise. Fourthly $\operatorname{cov}\left(u_{t}, x_{t}\right)=0$ illustrating that the residuals are not correlated with risk factors, that is the independent variables and hence absence of multicollinearity. Lastly the normality assumption $u_{t} \sim N\left(0, \sigma^{2}\right)$ requires data to have the characteristics of a normal distribution, thus skewness and excess kurtosis will equal zero. In reality this may not be the case for asset returns, however the Jarque-Bera test will substantiate the matter.

If the first four assumptions are not violated, then the constant coefficient represented by $\alpha$ and the beta coefficient/s will be BLUE. B (Best) implies that the OLS beta coefficient will have the minimum variance among all linear unbiased estimators. L (Linear) signifies that the constant and beta coefficient are a linear combination for the dependent variable $y$. U (Unbiased) means that on average the constant and beta coefficient will be equivalent to their true values. E (Estimator) insinuates that the estimated regressors for $\alpha$ and $\beta$ represent the true values of alpha and beta (Brooks, 2008).

\section{Dataset and Residual Diagnostics Results}

This section illustrates the results emanating from the pre- and post-regression tests namely the ADF unit root test, the KPSS stationarity test, the Jarque-Bera normality test, the Durbin Watson serial correlation test, the Breusch-Godfrey autocorrelation test, the White heteroscedasticity test and the ARCH test.

The ADF and KPSS tests are performed for all the equally weighted portfolios, market proxies, risk-free rate and all the exogenous variables to assess whether they exhibit stationary or unit root trends. A priori, raw data for all variables was expected to display random walk characteristics, and this was unsurprisingly confirmed, supported by large P-values in the ADF test and likewise by sizeable LM stats in the KPSS. As mentioned earlier, this data characteristic is not desirable and requires alteration to stationarity, thus becoming fit for regression analysis via OLS. For illustration purposes 
the endogenous variable US_MF_GF_US_IR_PORTFOLIO (Fig. 1) required data transformation from raw unit root data till $\mathrm{LN}\left(x / x_{-1}\right)$ modification to stationarity. The $\mathrm{LN}\left(\mathrm{NAV} / \mathrm{NAV}_{-1}\right)$ is subsequently employed as LN(NAV) was not sufficient to induce stationarity.

When applying $\mathrm{LN}\left(x / x_{-1}\right)$ on the monthly NAVs, the change on previous month is calculated hence losing a single observation from the dataset. After the $\mathrm{LN}\left(\mathrm{NAV} / \mathrm{NAV}_{-1}\right)$ modification, the data sample now ranges from January 2004 to December 2014, implying 10 financial years. This adjustment is crucial as all data was transformed into a stationary time series.

Equally important, due to the non-normality nature of the dataset as confirmed by the Jarque-Bera, the $\mathrm{LN}\left(x / x_{-1}\right)$ is employed to approximate normality. Nevertheless when dealing with asset returns, it is a regular procedure to allow for non-normality by assuming normality (Black \& Scholes, 1973; Falzon \& Castillo, 2013). The Jarque-Bera normality test jointly with the distribution graphs confirm that on average all data is nonnormal distributed except for SMB_EU, SMB, HML_EU, whilst also demonstrate negatively skewed data except for the HML_EU and HML independent variables. Furthermore the data is leptokurtic rather than mesokurtic, given that excess kurtosis is repeatedly exhibiting a positive integer. Summing
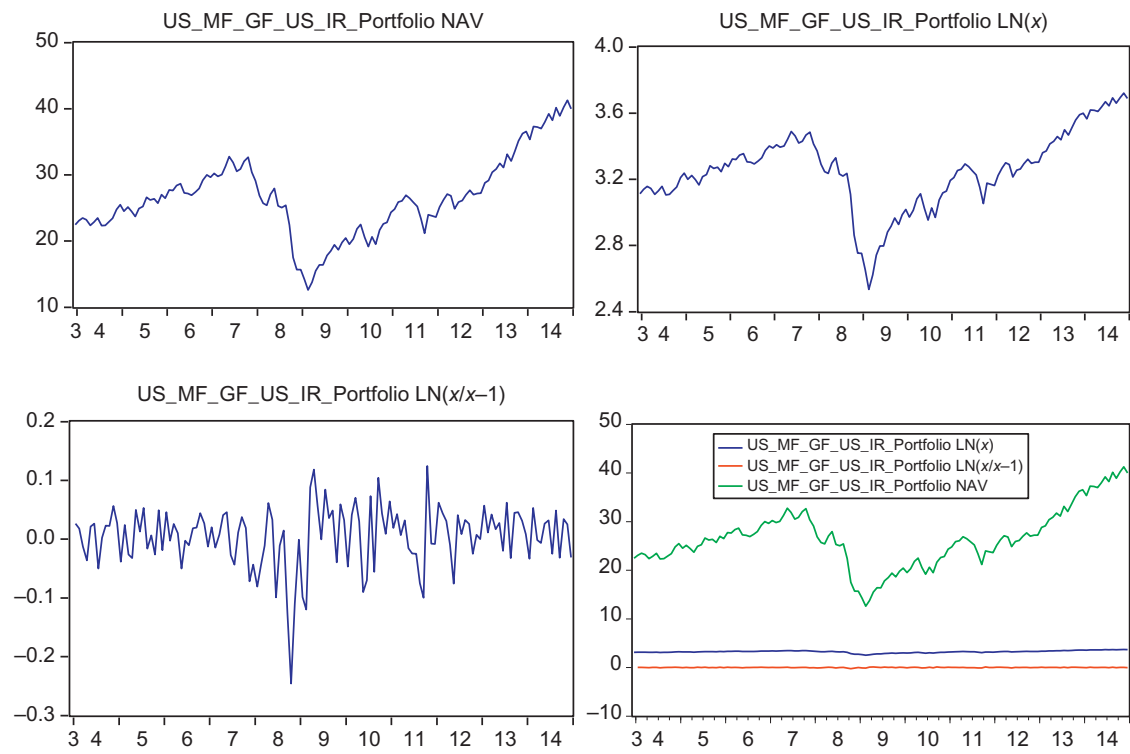

Fig. 1. US_MF_GF_US_IR_PORTFOLIO. 
up, this overall negative skewness implies frequent small gains and few but large extreme losses, where such downside is further amplified by a positive and large kurtosis, given that extreme observations are more likely vis-à-vis a mesokurtic. Given these results EU_MF_GF_EU_ACT_PORTFOLIO is the most risky portfolio indicating the largest negative skewness and the highest positive kurtosis, signifying a left skewed leptokurtic distribution.

Moving on to residual diagnostics, auto correlation for the three asset pricing models is practically inexistent, with only minor occurrence. The residuals' auto correlation is examined via the Durbin Watson for lag 1 and Breush Godfrey for $\operatorname{lag}(\mathrm{s}) 1,2,6$ and 12. This was done to investigate any presence of monthly, two months, semi-annually and annual auto correlation. The null hypothesis of no serial correlation in residuals for the three asset pricing models was virtually never rejected and hence no assumption of CLRM was violated. At the $95 \%$ confidence interval, autocorrelation was only accepted in 11 instances from 144 cases, mainly for index replication portfolios at lag 12. This may indicate the existence of a specific pattern at lag 12 and indeed a seasonality dummy variable may be employed to capture the presence of such effects.

The White test, another residual diagnostic, confirms that error terms are predominantly homoscedastic for all employed asset pricing models including their extensions, signifying no or slight violation of CLRM. Indeed for the three standard asset pricing models, at the $95 \%$ confidence level the null hypothesis of homoscedasticity is accepted for 30 instances from 36 cases. Furthermore given the nature of financial markets, the frail presence of non-constant variances is accepted by notable papers (Falzon \& Castillo, 2013). This result is further confirmed by the ARCH test, indicating trivial ARCH effects among the dataset. The fact that residuals are overall homoscedastic and no significant ARCH effects are present, GARCH type model and its variants are not appropriate and hence are overlooked. This ensued as the error terms exhibited characteristics which are desirable by OLS, and hence orthodox regression analysis methods are exploited.

\section{RESULTS AND ANALYSIS}

Recall that central to this chapter is the question of whether investors should be inclined towards any particular investment style between active and passive management, given the examined risk-adjusted performance and alphas. Such examinations are considered robust given that no or trivial violations of CLRM are encountered as by the pre- and post-regression tests. 


\section{Orthodox Asset Pricing Models Results}

As a starting point the asset pricing models outcomes are based on the assumption that a positive linear relationship subsists between risk and return. This is crucial to highlight as specific research negates that such assumption holds in theory, thereby underlining no relationship or even the existence of a trade-off between risk and return (Campbell, 1987; Merton, 1973; Whitelaw, 1994; Zhang \& Jacobsen, 2014). Nonetheless the hypothesis that return can be explained by various forms of risk, a case in point is via multi-factor models, has been widely analysed and applied in numerous distinguished research papers (Black et al., 1972; Carhart, 1997; Chen et al., 1986; Fama, 1968; Fama \& French, 1993; Fama \& Macbeth, 1973; Jensen, 1968; Lintner, 1965; Mossin, 1966; Sharpe, 1964; Treynor, 1961). Accordingly this research together with the ensuing regression analysis and results examination is deemed authentic and valid.

For the upcoming regression models (Tables 3-5), the alpha, $\alpha$, coefficient measures the extent to which portfolio managers given the underlying risk are either creating exceptional gains over and above the market portfolio or otherwise. Evidently this coefficient is desired to be positive as negative results signify deterioration of value. The market's $\beta_{1}$ measures the concurrent impact of the changes in the market benchmark on the funds' portfolio returns, where predictably results are found to be highly statistically significant and positively related. The risk factor loadings' betas, $\beta_{2}$ (SMB), $\beta_{3}$ (HML) and $\beta_{4}$ (MOM) evaluate the concurrent exposure to the small size effect, value risk factor and momentum variable, respectively. Put simply the higher the beta coefficient, the larger the exposure to the prior mentioned risk factors, which are solely authentic in case of statistical significance.

Moving to the actual research findings, on average it is prevalent that fund managers' skill or luck is inexistent, as denoted by the constant coefficient in the regression equations symbolised by alpha (Tables 3-5). Indeed the solitary presence of positive alpha is exhibited by a class of ETFs specifically EU_ETF_GF_EU_IR_PORTFOLIO. This may seem peculiar since index replication structures simply aim to track an underlying benchmark rather than outperform the market. However an essential reminder is that EU_ETF_GF_EU_IR_PORTFOLIO's constituents have dissimilar benchmarks, and hence not necessarily track the EUROSTOXX equity index. The presence of alpha for passively managed funds is therefore not an anomaly but simply a justification that on average the constituents are tracking a superior benchmark in terms of risk-adjusted returns. 
Table 3. Capital Asset Pricing Model Regression Results.

Capital Asset Pricing Model

Model Results

\begin{tabular}{llcc}
\hline Series & \multicolumn{1}{c}{$\alpha$} & Market & Adjusted $R^{2}$ \\
\hline EU_ETF_GF_EU_IR_PORTFOLIO & $-0.0029^{* *}$ & $0.9996^{* * *}$ & 0.9996 \\
EU_ETF_GF_US_IR_PORTFOLIO & -0.0005 & $1.0038^{* * *}$ & 0.9987 \\
EU_MF_GF_EU_ACT_PORTFOLIO & -0.0037 & $0.9963^{* * *}$ & 0.9959 \\
EU_MF_GF_EU_IR_PORTFOLIO & -0.0007 & $1.0006^{* * *}$ & 0.9992 \\
EU_MF_GF_US_ACT_PORTFOLIO & -0.0001 & $0.9984^{* * *}$ & 0.9988 \\
EU_MF_GF_US_IR_PORTFOLIO & -0.0012 & $1.0005^{* * *}$ & 0.9979 \\
US_ETF_GF_EU_IR_PORTFOLIO & -0.0011 & $0.9981^{* * *}$ & 0.9984 \\
US_ETF_GF_US_IR_PORTFOLIO & -0.0005 & $0.9985^{* * *}$ & 0.9998 \\
US_MF_GF_EU_ACT_PORTFOLIO & -0.0009 & $0.9959^{* * *}$ & 0.9973 \\
US_MF_GF_EU_IR_PORTFOLIO & -0.0003 & $0.9982^{* * *}$ & 0.9977 \\
US_MF_GF_US_ACT_PORTFOLIO & -0.0011 & $0.9978^{* * *}$ & 0.9991 \\
US_MF_GF_US_IR_PORTFOLIO & -0.0003 & $0.9988^{* * *}$ & 0.9996 \\
\hline
\end{tabular}

Notes: ${ }^{*}, * *$ and $* * *$ signify rejection of the null hypothesis that $\alpha$ or $\beta=0$ at $10 \%, 5 \%$ and $1 \%$ significant level, respectively.

Model: $\ln \Delta R_{p i, t}-\ln \Delta R_{f, t}=\alpha_{i}+\beta_{i 1}\left\{\ln \Delta R_{m i, t}-\ln \Delta R_{f, t}\right\}+\varepsilon_{i, t}$.

Market portfolio is either S\&P500 or EUROSTOXX depending on geographical focus. As a side analysis, DAX \& MSCI EU and MSCI US are employed as market portfolios for their respective regions. N.B. No significant differences from the above are obtained.

Exogenous variables are given lagged and lead values for further empirical tests, however residual terms are found to be heteroscedastic, without finding ARCH effects.

For the remaining portfolios, results demonstrate that calculated alphas are not statistically different from zero. This entails that considering the employed market portfolios for the relevant region, 11 equally weighted portfolios irrespective of whether they are actively or passively managed are not adding value over and above their market benchmarks. For index tracking funds this upshot was anticipated, as their purpose is merely to replicate market return rather than to outperform. Yet, the outcome was fairly unexpected and disappointing that none of the four active equity fund portfolios produced any positive alphas. Evidently this doesn't signify that none of the actively managed mutual funds constituents in the equally weighted portfolios were able to outperform the market. Indeed specific active funds might have indeed outperformed the market.

The reality is that the top active funds are concealed by the underperformance of their peers forming part of the portfolio. Nonetheless identifying the best actively managed funds prior exhibiting superior performance is a huge task. Selecting active funds simply on historical performance may be 
Table 4. Fama French Three-Factor Model Regression Results.

\begin{tabular}{|c|c|c|c|c|c|}
\hline \multicolumn{6}{|l|}{ Three-Factor Model } \\
\hline \multicolumn{6}{|l|}{ Model Results } \\
\hline Series & $\alpha$ & Market & SMB & HML & $\begin{array}{l}\text { Adjusted } \\
\qquad R^{2}\end{array}$ \\
\hline EU_ETF_GF_EU_IR_PORTFOLIO & $-0.0030 * * *$ & $0.9994 * * *$ & -0.0007 & -0.0004 & 0.9996 \\
\hline EU_ETF_GF_US_IR_PORTFOLIO & -0.0003 & $1.0030^{* * *}$ & -0.0008 & -0.0017 & 0.9987 \\
\hline EU_MF_GF_EU_ACT_PORTFOLIO & -0.0035 & $0.9957 * * *$ & -0.0010 & -0.001 & 0.9959 \\
\hline EU_MF_GF_EU_IR_PORTFOLIO & -0.0007 & $1.0005^{* * *}$ & -0.0004 & -0.0001 & 0.9991 \\
\hline EU_MF_GF_US_ACT_PORTFOLIO & -0.0002 & $0.9981 * * *$ & -0.0003 & -0.0007 & 0.9988 \\
\hline EU_MF_GF_US_IR_PORTFOLIO & -0.0009 & $0.9998 * * *$ & -0.0020 & -0.0020 & 0.9979 \\
\hline US_ETF_GF_EU_IR_PORTFOLIO & -0.0008 & $0.9988^{* * *}$ & $-0.0027 * *$ & -0.0007 & 0.9985 \\
\hline US_ETF_GF_US_IR_PORTFOLIO & -0.0001 & $0.9986^{* * *}$ & $-0.0027 * * *$ & -0.0008 & 0.9998 \\
\hline US_MF_GF_EU_ACT_PORTFOLIO & -0.0004 & $0.9971 * * *$ & $-0.0041 * * *$ & -0.0012 & 0.9974 \\
\hline US-MF_GFE-ËIR_PORTFOLIO & -0.0001 & $0.9993 * * *$ & $-0.0039 * * *$ & -0.0013 & 0.9978 \\
\hline US_MF_GF_US_ACT_PORTFOLIO & -0.0018 & $0.9985^{* * *}$ & $-0.0044 * * *$ & $-0.0024 *$ & 0.9992 \\
\hline US_MF_GF_US_IR_PORTFOLIO & -0.0009 & $0.9989^{* * *}$ & $-0.0038 * * *$ & -0.0011 & 0.9996 \\
\hline
\end{tabular}

Notes: $* * *$ and $* * *$ signify rejection of the null hypothesis that $\alpha$ or $\beta=0$ at $10 \%, 5 \%$ and $1 \%$ significant level, respectively.

Model: $\ln \Delta R_{p i, t}-\ln \Delta R_{f, t}=\alpha_{i}+\beta_{i 1}\left\{\ln \Delta R_{m i, t}-\ln \Delta R_{f, t}\right\}+\beta_{i 2}\left\{\mathrm{SMB}_{t}\right\}+\beta_{i 3}\left\{\mathrm{HML}_{t}\right\}+\varepsilon_{i, t}$.

Market portfolio is either S\&P500 or EUROSTOXX depending on geographical focus. As a side analysis, DAX \& MSCI EU and MSCI US are employed as market portfolios for their respective regions. N.B. No significant differences from the above are obtained.

Exogenous variables are given lagged and lead values for further empirical tests, however residual terms are found to be heteroscedastic, without finding ARCH effects.

Fama French US research factors are employed for US equity portfolios and European research factors are applied for European stock portfolios. When applying US research factors for European exposed equity portfolio funds and vice versa, weaker explanatory power is found.

an expensive option and undeniably, mutual funds displaying an excellent past performance don't guarantee outperformance in the future. Indeed literature suggests that the top performing funds in any one decade tend to be completely different from the preceding and subsequent period (Greenblatt, 2011), indicating imprudence in choosing mutual funds based on their past performance. This has a twofold effect, primarily in terms of underperformance but may also apparently ensue into higher fees reflecting higher demand given the mutual fund popularity.

From a risk-adjusted return perspective in view of the 12 equally weighted portfolios, there is practically no diversity between active and passive management style for the studied decade. Put simply with the exception of a class of European ETFs tracking European indices, an investor will be indifferent when choosing between the two structures in the absence of transaction costs. Nevertheless in reality friction costs play a crucial role 
Table 5. Carhart Four-Factor Model Regression Results.

Four-Factor Model

Model Results

\begin{tabular}{lcccccc}
\hline Series & $\alpha$ & Market & SMB & HML & MOM & Adjusted $R^{2}$ \\
\hline EU_ETF_GF_EU_IR_PORTFOLIO & $-0.0029^{* *}$ & $0.9994^{* * *}$ & -0.0007 & -0.0003 & -0.0002 & 0.9996 \\
EU_ETF_GF_US_IR_PORTFOLIO & -0.0006 & $1.0041^{* * *}$ & -0.0010 & -0.0016 & -0.0013 & 0.9987 \\
EU_MF_GF_EU_ACT_PORTFOLIO & -0.0041 & $0.9958^{* * *}$ & -0.0010 & -0.0004 & -0.0007 & 0.9959 \\
EU_MF_GF_EU_IR_PORTFOLIO & -0.0007 & $1.0006^{* * *}$ & -0.0004 & -0.0002 & -0.0001 & 0.9991 \\
EU_MF_GF_US_ACT_PORTFOLIO & -0.0000 & $0.9992^{* * *}$ & -0.0007 & -0.0009 & $-0.0050^{* *}$ & 0.9988 \\
EU_MF_GF_US_IR_PORTFOLIO & -0.0011 & $1.0009^{* * *}$ & -0.0022 & -0.0018 & -0.0006 & 0.9978 \\
US_ETF_GF_EU_IR_PORTFOLIO & -0.0014 & $0.9987^{* * *}$ & $-0.0026^{* *}$ & -0.0000 & -0.0008 & 0.9985 \\
US_ETF_GF_US_IR_PORTFOLIO & -0.0001 & $0.9986^{* * *}$ & $-0.0027^{* * *}$ & -0.0007 & -0.0013 & 0.9998 \\
US_MF_GF_EU_ACT_PORTFOLIO & -0.0016 & $0.9969^{* * *}$ & $-0.0040^{* * *}$ & -0.0001 & $-0.0013^{*}$ & 0.9974 \\
US_MF_GF_EU_IR_PORTFOLIO & -0.0009 & $0.9992^{* * *}$ & $-0.0039^{* * *}$ & -0.0002 & $-0.0013^{*}$ & 0.9979 \\
US_MF_GF_US_ACT_PORTFOLIO & -0.0012 & $0.9962^{* * *}$ & $-0.0044^{* * *}$ & -0.0015 & $-0.0041^{* *}$ & 0.9992 \\
US_MF_GF_US_IR_PORTFOLIO & -0.0007 & $0.9980^{* * *}$ & $-0.0037^{* * *}$ & -0.0008 & -0.0019 & 0.9996 \\
\hline
\end{tabular}

Notes: *,** and *** signify rejection of the null hypothesis that $\alpha$ or $\beta=0$ at $10 \%, 5 \%$ and $1 \%$ significant level, respectively.

Model: $\ln \Delta R_{p i, t}-\ln \Delta R_{f, t}=\alpha_{i}+\beta_{i 1}\left\{\ln \Delta R_{m i, t}-\ln \Delta R_{f, t}\right\}+\beta_{i 2}\left\{\mathrm{SMB}_{t}\right\}+\beta_{i 3}\left\{\mathrm{HML}_{t}\right\}+\beta_{i 4}\left\{\mathrm{MOM}_{t}\right\}+\varepsilon_{i, t}$.

Market portfolio is either S\&P500 or EUROSTOXX depending on geographical focus. As a side analysis, DAX \& MSCI EU and MSCI US are employed as equity market portfolios for their respective regions. N.B. No significant differences from the above are obtained.

Exogenous variables are given lagged and lead values for further empirical tests, however residual terms are found to be heteroscedastic, without finding ARCH effects.

Fama French US research factors are employed for US equity portfolios and European research factors are applied for European stock portfolios. When applying US research factors for European exposed equity portfolio funds and vice versa, weaker explanatory power is found.

when selecting an investment structure particularly in instances where the financial instruments yield a similar cash flow or more importantly identical risk-adjusted returns. Another consideration which plays an essential role and is understood to be higher for actively managed funds are agency costs. This indicates that in discretionary management active fund managers may not always perform their duties in the best interests of investors. A classic scenario is where portfolio managers have incentives to take on more risks which may not be desirable from the investors' point of view. Conversely for passively managed structures, the actual management is usually much more clearly defined and the only hazard is the tracking error.

The revealed alphas emphasise a pivotal role for the cost factor and hence decisive in an investment decision. It is of general knowledge that the cost structure of passively managed funds is more favourable, since the sole objective of the latter is to track an underlying index. Conversely active funds engage their efforts in searching for mispriced securities, undertaking a more complex process and eventually more costly. 
Given the exposed results, for the typical investor who doesn't seek regular monitoring, but is more concerned about a longer term horizon and hence growth, it is advisable to opt for a low-cost passive equity fund or ETF. However this is easier said than done, as there is a wide spectrum of index replication structures for investors to choose from namely ranging from cap size, style that is value, growth or blend, sector category, region, etc., and consequently a financial advisor is required for novice investors. For such investors who may also lack financial literacy, it is prudent to elect passive funds which track the general market such as the Standard \& Poor's 500 and the EUROSTOXX, or may diversify further by creating a portfolio of passive funds. Passive structures can be chosen depending on the desired regional exposure, sector and exposure to foreign exchange. Nonetheless investors can still be exposed to overseas markets without having a foreign exchange exposure, by choosing funds with the same currency denomination which are daily hedged, and hence not capturing currency risk.

\section{Portfolios' Characteristics Analysis}

Examination of the equity fund portfolios' degree of fluctuation as measured by market risk depicts an ETF portfolio EU_ETF_GF_US_IR_PORTFOLIO, exhibiting the highest volatility in all three asset pricing models. Hence an index replication structure does not necessarily provide a lower standard deviation or inferior beta risk as this is dictated by the behaviour of the underlying benchmark. Conversely US_MF_GF_EU_ACT_PORTFOLIO, an actively managed mutual fund portfolio displayed the weakest shocks in both CAPM and Three-Factor Model, whilst another actively managed mutual fund portfolio, EU_MF_GF_EU_ACT_PORTFOLIO revealed the lowest market risk in the Four-Factor Model. In fact market betas for active fund portfolios, on average are lower than their peers. Given regression results, active fund portfolios are less volatile than the employed market benchmarks which could imply that whilst active investors are charged higher fees due to identification of undervalued and overvalued securities, fund managers may be conservative in the process of stock picking. Conversely it can be viewed that on average active mutual funds provide more stability given smaller betas, and hence enhanced peace of mind especially for active risk averse investors, even though this might mean higher costs. The absence of statistically significant positive alphas could ensue from the lack of appetite revealed by active fund managers to detect bargains. The solitary fund portfolio exhibiting a statistically significant positive alpha, EU_ETF_GF_EU_IR_PORTFOLIO, is a relatively cautious index replication 
portfolio as illustrated by a beta below one. Another reason could be that fund managers try to spot opportunities, yet the identified undervalued or overvalued equities could endure the mispricing in the long run and hence not returning to their intrinsic value, due to model risk.

Investigation of portfolios' investment styles proves that US equity fund portfolios have a positive exposure to small caps, and the effect is even stronger for actively managed mutual funds. Put simply, active portfolio managers may search for such exposure, since research authenticates the general outperformance of small caps over large ones (Banz, 1981; Fama \& French, 1993), however this effect was not statistically significant and thus not present in the case of European equity fund portfolios. Also for the HML risk factor, no particular preference or exposure among value or growth stocks was revealed, except for a single portfolio US_MF_GF_US_ACT_PORTFOLIO, which showed a statistically significant negative beta in the Three-Factor Model implying an overexposure to growth equities. As for the momentum risk factor, three out of four active fund portfolios have a statistically significant exposure. More specifically two active fund portfolios, EU_MF_GF_US_ACT_PORTFOLIO and US_MF_GF_US_ACT_PORTFOLIO pursue a momentum strategy, whilst another actively managed fund portfolio, US_MF_GF_EU_ACT_PORTFOLIO employs contrarian and reversal strategies. Lastly the adjusted $R^{2}$ in all regressions for all the three asset pricing models is found to be relatively high, signifying that on average the models are describing an adequate proportion of the variation in the equally weighted equity fund portfolios' returns implying adequately explained results.

\section{Hybrid Equity Mutual Funds}

The absence of positive alphas indicates that the nightmare for portfolio managers continues, as they consistently fail to beat market benchmarks. This downside can be straightforwardly resolved by switching to passive styles by tracking market benchmarks, also benefiting investors owing to the lower charges. Nonetheless if the majority of fund managers turn passive, competition for information declines and fewer participants will try to outperform the market, leading to market inefficiency. At this point, given the assumed existence of a trade-off between market efficiency and abnormal returns, arbitrage opportunities will become prevalent magnetising the attention of market participants. This will again attract fund managers to perform active management to benefit from such existing and potential 
opportunities. Theoretically it may be one explanation to Gruber (1996) mutual funds puzzle, apart from the mutual funds' hard selling and investors' lack of financial literacy. However as portfolio managers switch back to active management, market efficiency increases again, thereby reducing the likelihood of abnormal returns and presence of arbitrage.

Understandably investment managers and their fund structures may not be flexible due to a variety of friction costs and barriers halting them from a rapid switch. Barriers for altering from passive to active and vice versa may include regulatory constraints, legal costs, non-compliance of prospectus among other changing costs that arise in the process. Also funds may not wholly employ a discretionary investment management policy and thus any transfer of clients' assets may require prior approval, leading to time lag hence defeating the scope of flexibility. Yet an equity fund can avoid these costs by straightaway stressing its intentions in the prospectus to operate as a hybrid, that is, altering from passive to active style depending on changes in market efficiency. Such a fund structure may not yield any benefits in consistently highly efficient markets. Yet this fund structure may be valuable for less constantly efficient markets such as emerging markets, where the flow of information may not be uniformly reflected in asset prices. Such vehicle should also promote a costeffective fee structure including a cheaper expense ratio, given that it does not undertake active management on an ongoing basis.

\section{Active Management Costs as a Subsidy for Market Efficiency}

The dilemma remains whether active management provides any benefits at all. From a market structure point of view, active mutual funds are crucial for keeping high levels of market efficiency. However from the investors' perspective given these results, the benefits sought are questionable especially in the light of higher fees. In general, high levels of market efficiency are positive for investors as financial instruments' prices reflect all the available information. But maintaining market efficiency doesn't come automatic but rather the system creates incentives in inefficient markets for participants to exploit. Yet when markets are already highly efficient, it is not clear as to why mutual funds persist in charging high fees when opportunities are practically 'inexistent'. One possible explanation could be due to menu costs. Certainly the high fees paid by active investors help in preserving market efficiency and indirectly subsidise passive investors' costs. Put simply passive investors are the free riders of the fund industry profiting from enhanced market efficiency at lower costs due to an intrinsic cost 
charged by the 'market system' to active investors. Hence part of the fees paid by active investors rather for alpha creation may be deemed as a natural cost imposed by the 'market structure' to maintain market efficiency by supporting and encouraging fund managers to retain market efficiency.

This natural cost for keeping market efficiency is vital from the system's perspective, yet still a cost for active investors as calculated alphas for active fund portfolios do not appear to compensate for this drawback. Nonetheless the results confirm that although on average no positive alphas have been generated in the last decade, no statistically significant negative alphas were produced neither. This finding is important since it clearly indicates the huge influence of the market benchmarks on the distinct equity fund portfolios, as exhibited by the highly statistically significant market beta coefficients proxying market risk in the three asset pricing models. Put simply in booming markets, funds generally enjoy good returns and vice-versa, except in cases where an inverse strategy is employed. Hence active management for the typical investor is deemed as a caveat emptor, as a passive instrument or index replication structure will perform very well especially given its low cost composition, also considering that the tracking error is well managed.

\section{CONCLUSION}

The study provides evidence that neither active nor passive management style is superior in terms of risk-adjusted performance when analysing solely NAVs for a 10-year timeframe. Nevertheless investors are instinctively informed of the higher expenses associated with actively managed mutual funds, such as initial fees which can range from $2 \%$ and over including higher annual expense ratios, amongst other possible costs. Investors shouldn't overlook the heftier fees charged by mutual funds, as these have a massive bearing on portfolio returns. Indeed an investor with a 100,000 worth of investment capital and a 20-year horizon seeking a USLarge Cap Growth equity fund is expected to lose 170,644 due to higher costs, if an actively managed mutual fund such as Morgan Stanley's with an expense ratio of $1.69 \%$ is elected over a Charles Schwab ETF, which has a matching objective but is accessible at a hugely cheaper expense ratio of $0.07 \%$. The assumptions for this calculation are a market expected annual rate of return of $10 \%$, ensuing into a cost-adjusted return rate of $8.31 \%$ and $9.93 \%$ leading to a final balance of 493,595 and 664,239 for the active and passive structures, respectively. Certainly this calculation is 
overlooking the initial fees for both cases, where for the actively managed mutual fund it is in the region of $5.75 \%$, whereas for the ETF transaction costs are equivalent to when purchasing a stock. Again the discrepancy is substantial, yet this illustration shouldn't be taken as a blue print as other active equity funds might be more cost efficient than demonstrated in this specimen and indeed anomalies do exist. For instance if an investor desires exposure to the US Healthcare sector, iShares US Healthcare ETF is available at an expense ratio of $0.45 \%$, whereas Vanguard's actively managed Healthcare mutual fund supplies an expense ratio of $0.34 \%$. Using the aforementioned calculation, at a market expected annual rate of return of $10 \%$, cost-adjusted return rates are of $9.55 \%$ and $9.66 \%$ leading to a final balance of 619,794 and 632,361 for the ETF and active structure, respectively. This demonstrates that the active fund is cheaper than the corresponding ETF, and will indeed deliver an added value of 12,567 over its competitor. Yet if tax advantages of ETFs are considered in the equation, the balance will easily favour the ETF over the active mutual fund, especially in the case of long horizon and high net worth investors.

This leads to resolve that it is prudent not to generalise about whether active or passive management is unquestionably superior to its peer and to analyse on a case-by-case basis. Simultaneously investors are subliminally informed that on average passive vehicles are more cost-effective, whereas ETFs provide higher tax advantages. Categorically decisive for investors is the access to the cheapest available investment structure for their investment objective, regardless of being an active mutual fund, passive mutual fund or index replication ETF.

\section{LIMITATIONS AND RECOMMENDATIONS FOR FUTURE RESEARCH}

The primary shortcoming of this research is the employment of an equity benchmark as opposed to a well-diversified market portfolio, which in theory (Roll, 1977) would have to encompass the entire asset universe including commodities, currencies, real estate, precious metals inter alia. This signifies that alpha generation and risk-adjusted returns are not computed on all available investments opportunities and that the true and actual returns are unobservable.

Secondly, the application of an equity benchmark implies that both active and passive equity funds are disadvantaged when evaluated with 
the former, as it is a purely theoretical concept. Put simply this comparison does not have a bearing on investors in practice, as it does not actually show investors' opportunity set and investment choices. The closest real life structures to equity indices and thus more realistic benchmarks are index replication structures such as index mutual funds and ETFs. This is since as opposed to an index mutual fund, pure theoretical equity benchmarks like the Standard \& Poor's 500 do not illustrate the expenses undertaken in replicating an underlying benchmark. The bottom line of this limitation is that risk-adjusted returns and generated alphas for both active and passive equity funds will be lower than they actually are. Nonetheless utilising the aforesaid equity benchmarks for both active and passive equity funds result in the identical yardstick without favouring a management style or investment vehicle over another.

Thirdly, the recently enhanced popularity and growth of ETFs signifies lack of historical data for these investment structures. Indeed adequate data availability for ETFs can be traced back for a period of 10 years, with data accessibility reducing exponentially when exceeding such timeframe.

Fourthly, the assessment of active and index replication vehicles via a portfolio approach ensues in findings for fund categories, but conceals outcomes for top performing and worst performing equity funds. Nevertheless as a side analysis, assessment of individual equity funds demonstrated undesirable OLS characteristics and therefore non robust results.

After analysing the empirical work of this study jointly with the present literature review relating to active and passive management, a list of new research ideas emerge. Principally, the majority of the research is only concerned with developed equity mutual funds and equity ETFs, with no reference to any other asset classes and/or emerging/frontier markets. This presents a literature gap to analyse active and index replication equity funds, predominantly ETFs, in emerging and frontier markets, primarily given the relative diverse levels of market efficiency. Additionally it presents an opportunity to undertake a comparison between active and passive management for other asset classes including bonds, commodities, mixed assets and real estate primarily REITs (Real Estate Investment Trusts).

\section{NOTE}

1. Twelve equally weighted portfolios require 12 CAPM regressions, 12 ThreeFactor model regressions and 12 Four-Factor model regressions. 


\section{REFERENCES}

Aber, J. W., Li, D., \& Can, L. (2009). Price volatility and tracking ability of ETFs. Journal of Asset Management, 10, 210-221.

Agapova, A. (2009). Innovations in financial products: Conventional mutual index funds versus exchange traded funds. Journal of Financial Markets, 14, 323-343.

Andreu, L., Swinkels, L. A. P., \& Tjong-A-Tjoe, L. (2012). Can exchange traded funds be used to exploit country and industry momentum? Retrieved from http://ssrn.com/ abstract $=1150972$. Accessed on January 15, 2015.

Banz, R. W. (1981). The relationship between return and market value of common stocks. Journal of Financial Economics, 9, 3-18.

Basu, S. (1977). Investment performance of common stocks in relation to their price-earnings ratios: A test of efficient market hypothesis. Journal of Finance, 32(3), 663-682.

Bernstein, J. P. (2002). A primer on exchange-traded funds. Journal of Accountancy, 193(1), $38-41$.

Black, F., Jensen, M. C., \& Scholes, M. (1972). The capital asset pricing model: Some empirical tests. In M. Jensen (Ed.), Studies in the theory of capital markets (pp. 79-121). New York, NY: Praeger Publishers.

Black, F., \& Scholes, M. (1973). The pricing of options and corporate liabilities. Journal of Political Economv, 81(3), 637-654.

Blake, C. R., Elton, E. J., \& Gruber, M. J. (1993). The performance of bond mutual funds. The Journal of Business, 66(3), 371-403.

Bogle, J. C. (1998). The implications of style analysis on mutual fund performance evaluation. Keynote Speech.

Brooks, C. (2008). Introductorv econometrics for finance (2nd ed.). Cambridge: Cambridge University Press.

Campbell, J. Y. (1987). Stock returns and the term structure. Journal of Financial Economics, $18,373-399$.

Carhart, M. M. (1997). On persistence in mutual fund performance. The Journal of Finance, $52,57-82$.

Chen, N., Roll, R., \& Ross, S. (1986). Economic forces and the stock market. Journal of Business, 59(3), 383-403.

Dellva, W. L. (2001). Exchange-traded funds not for everyone. Journal of Financial Planning, $14,110-124$.

Elton, E. J., Gruber, M. J., Comer, G., \& Li, K. (2002). Spiders: Where are the bugs? Journal of Business, 75, 453-472.

Engle, R. F., \& Sarkar, D. (2006). Premiums-discounts and exchange traded funds. $\underline{\text { Journal of }}$ Derivatives, 13, 27-45.

Falzon, J., \& Castillo, D. (2013). A VAR approach to the analysis of the relationship between oil prices and industry equity returns. In J. Falzon (Ed.), Bank performance, risk and securitization. Basingstoke: Palgrave Macmillan.

Fama, E. F. (1968). Risk, return and equilibrium: Some clarifying comments. Journal of Finance, 23(1), 29-40.

Fama, E. F., \& French, K. R. (1992). The cross-section of expected stock returns. The Journal of Finance, 47(2), 427.

Fama, E. F., \& French, K. R. (1993). Common risk factors in the returns on stocks and bonds. Journal of Financial Economics, 33, 3-56. 
Fama, E. F., \& Macbeth, J. D. (1973). Risk, return, and equilibrium: Empirical tests. The Journal of Political Economy, 81(3), 607-636.

Frino, A., \& Gallagher, D. R. (2001). Tracking S\&P 500 index funds. Journal of Portfolio Management, 28(1), 44-55.

Gastineau, G. L. (2004). The benchmark index ETF performance problem. Journal of Portfolio Management, 30, 96-103.

Greenblatt, J. (2011). The big secret for the small investor (1st ed.). New York, NY: Crown Publishing Group.

Grossman, S. J., \& Stiglitz, J. E. (1980, June). On the impossibility of informationally efficient markets. The American Economic Review, 70(3), 393-408.

Gruber, M. J. (1996). Another puzzle: The growth in actively managed mutual funds. Journal of Finance, 51(3), 783-810.

Guedj, I., \& Huang, J. C. (2008). Are ETFs replacing index mutual funds? Retrieved from http://ssrn.com/abstract=1108728. Accessed on January 15, 2015.

Harper, J. T., Madura, J., \& Schnusenberg, O. (2006). Performance comparison between exchange-traded funds and closed-end country funds. International Financial Markets. Institutions \& Monev, 16, 104-122.

Jagannathan, R., \& Wang, Z. (1996). The conditional CAPM and the cross-section of expected returns. Journal of Finance, 51(1), 3-53.

Jegadeesh, N., \& Titman, S. (1993, March). Returns to buying winners and selling losers: Implications for stock market efficiency. Journal of Finance, 48(1), 65-91.

Jensen, M. C. (1968). The performance of mutual funds in the period 1945-1964. Journal of Finance, 23, 389-416.

Johnson, W. F. (2009). Tracking errors of exchange traded funds. Journal of Asset Management, 10, 253-262.

Kostovetsky, L. (2003). Index mutual funds and exchange-traded funds. Journal of Portfolio Management, 29, 80-93.

Kuo, T. W., \& Mateus, C. (2006). The performance and persistence of exchange-traded funds: Evidence for iShares MSCI country-specific ETFs. Paper presented at 2007 FMA Annual Meeting, Orlando, FL, USA.

Lintner, J. (1965). The valuation of risk assets and the selection of risky investments in stock portfolios and capital budgets. Review of Economics and Statistics, 47(1), 13-37.

Malkiel, B. G. (1995). Returns from investing in equity mutual funds 1971 to 1991. Journal of Finance, 50(2), 549-572.

Markowitz, H. M. (1952a). Portfolio selection. The Journal of Finance, 7(1), 77-91.

Markowitz, H. M. (1952b). The utility of wealth. The Journal of Political Economv, 60(2), $151-158$.

Merton, R. C. (1973). An intertemporal capital asset pricing model. Econometrica, 41. $\underline{867-887}$.

Minor, D. B. (2001). Beware of index fund fundamentalists. The Journal of Portfolio Management, 27(4), 45-50.

Mossin, J. (1966). Equilibrium in a capital asset market. Econometrica, 34(4). 768-783.

Poterba, J. M., \& Shoven, J. B. (2002). Exchange-traded funds: A new investment option for taxable investors. American Economic Review, 92, 422-427.

Roll, R. (1977). A critique of the asset pricing theory's tests part I: On past and potential testability of the theory. Journal of Financial Economics, 4(2), 129-176. 
Rompotis, G. G. (2006). Evaluating the performance and the trading characteristics of iShares. Retrieved from http://ssrn.com/abstract=946732. Accessed on January 15, 2015.

Rompotis, G. G. (2007). Evaluating the seasonality and persistence of ETFs performance and volatility: Implications for profitable investing. SSRN. Retrieved from http://ssrn.com/ abstract $=1022876$. Accessed on January 15, 2015.

Rompotis, G. G. (2008). An empirical comparing investigation of exchange traded funds and index funds performance. European Journal of Economics, Finance and Administrative Sciences, 13, 7-17.

Rompotis, G. G. (2009). Active vs. passive management: New evidence from exchange traded funds. Retrieved from http://ssrn.com/abstract $=1337708$

Ross, S. (1976). The arbitrage theory of capital asset pricing. Journal of Economic Theorv, 13(3), 341-360.

Sharpe, W. F. (1964). Capital asset prices - A theory of market equilibrium under conditions of risk. Journal of Finance, 19(3), 425-442.

Sharpe, W. F. (1966). Mutual fund performance. Journal of Business, 39(S1), 119-138.

Sharpe, W. F. (1991). The arithmetic of active management. The Financial Analysts' Journal, 47(1), 7-9.

Svetina, M., \& Wahal, S. (2008). Exchange traded funds: Performance and competition. Retrieved from http://ssrn.com/abstract $=1303643$. Accessed on January 10, 2015.

S\&P Indices. (2013). (SPIVA®) scorecard - S\&P Dow Jones indices. Retrieved from https:// www.google.com.mt/url?url=https://us.spindices.com/documents/spiva/spiva-us-yearend-2013.pdf\%3Fforce_download \%3Dtrue\&rct=j\&frm $=1 \& \mathrm{q}=\&$ esrc $=\mathrm{s} \& \mathrm{sa}=\mathrm{U} \& \mathrm{ei}=$ ZaU_VJWdMMXYywPlioDgCQ\&ved=0CBgQFjAB\&usg=AFQjCNFZwe_JtuCcrilI SNK8ORW4czNhOQ. Accessed on January 10, 2015.

S\&P Indices. (2014). (SPIVA®) scorecard - S\&P Dow Jones indices. Retrieved from http:// www.spindices.com/documents/spiva/spiva-us-mid-year-2014.pdf. Accessed on January $10,2015$.

Treynor, J. L. (1961). Market value, time, and risk. Unpublished manuscript. A final version was published in 1999. In R. A. Korajczyk (Ed.), Asset pricing and portfolio performance: Models, strategy and performance metrics (pp. 15-22). London: Risk Books.

Treynor, J. L. (1965). How to rate management of investment funds. Harvard Business Review, $43,63-75$.

Whitelaw, R. F. (1994). Time variations and covariations in the expectation and volatility of stock market returns. Journal of Finance, 49, 515-541.

Zhang, C. Y., \& Jacobsen, B. (2014). The Halloween indicator, 'Sell in May and go Away': An even bigger puzzle. Retrieved from http://ssrn.com/abstract=2154873. Accessed on January 10, 2015. 